Earth Common Journal Regular Issue The Voice of Change

MacEwan University

Volume 3, Number 1, September 2013

\title{
Climate Change Strategies 101
}

\author{
Donald E. Macdonald* \\ MacEwan University, Canada
}

\begin{abstract}
The development of climate change action plans and strategies is usually done via the policy cycle during the first half of a government's term. This shortterm political process is at odds with the longer-term climate change issue that requires a consistent and sustained effort. Consequently, this often leads to conflicting and ever changing climate plans and strategies that often do not fully move to implementation. Several key strategic questions need to be considered at the policy agenda setting stage. Examples of these questions include: the real impetus for developing the plan, political will to take on policy development at a particular time, the degree of intention to actually implement it, and depth of target versus costs to the economy. The developmental stage of climate plans in Canada has historically involved five key components (with many variations): 1) background policy and scientific work; 2) consultation process; 3) economic/policy analysis and target setting; 4) building political support for a greenhouse gas target and policy package to meet the target; and 5) refinement and final political approval. Businesses are also responding by developing climate change strategies to either hedge their risk of being regulated, hedge their risk related to severe weather events, and/or to take advantage of climate business opportunities.
\end{abstract}




\section{Introduction}

Governments around the world broadly accept the scientific conclusion that through the burning of fossil fuels and land clearing, humans are warming the planet and changing the climate. While the public perception may be that the scientific community is deeply divided on this question, the reality is that the vast majority of climate change papers (97\%) published since 1991 support this conclusion (Cook et al., 2013). Further, most governments have been developing climate change strategies and action plans to respond to this growing issue.

A climate change strategy or plan is essentially a government's policy intention to undertake a suite of actions to reduce greenhouse gas (GHG) emissions and/or to adapt to the changing climate. In Canada at least, this represents an official policy position of a government currently in power, but is generally not legally binding or enforceable. It can be compared to releasing a blueprint for a house you intend to build, but does not commit you to actually hiring a contractor. The terms "climate strategy" and "climate plan" or "climate action plan" are often used synonymously. However, some jurisdictions do apply a more rigorous definitional approach in which a strategy sets out broad goals (as GHG reduction targets) policy outcomes and measures, while an action plan tends to contain more specifics. It seems probable that some climate strategies/plans are more "green washing" and that the promoting government may never implement them. Where there exists a real intent to take action, more detailed implementation plans, legislation, regulations, incentive programs or other mechanisms that will attempt to deliver the strategies' goals and outcomes usually follow the climate strategies. For example, Canada has had a series of climate strategies and action plans, goals and targets that were introduced by several governments (and at least two political parties) but none were fully implemented (NRTEE, 2012). Businesses develop climate change strategies to either hedge their risk of being regulated, hedge their risk related to related severe weather events, and/or to take advantage of climate business opportunities. This paper outlines the role climate change strategies play for both government and businesses. 


\section{Government: Climate strategies and political cycles}

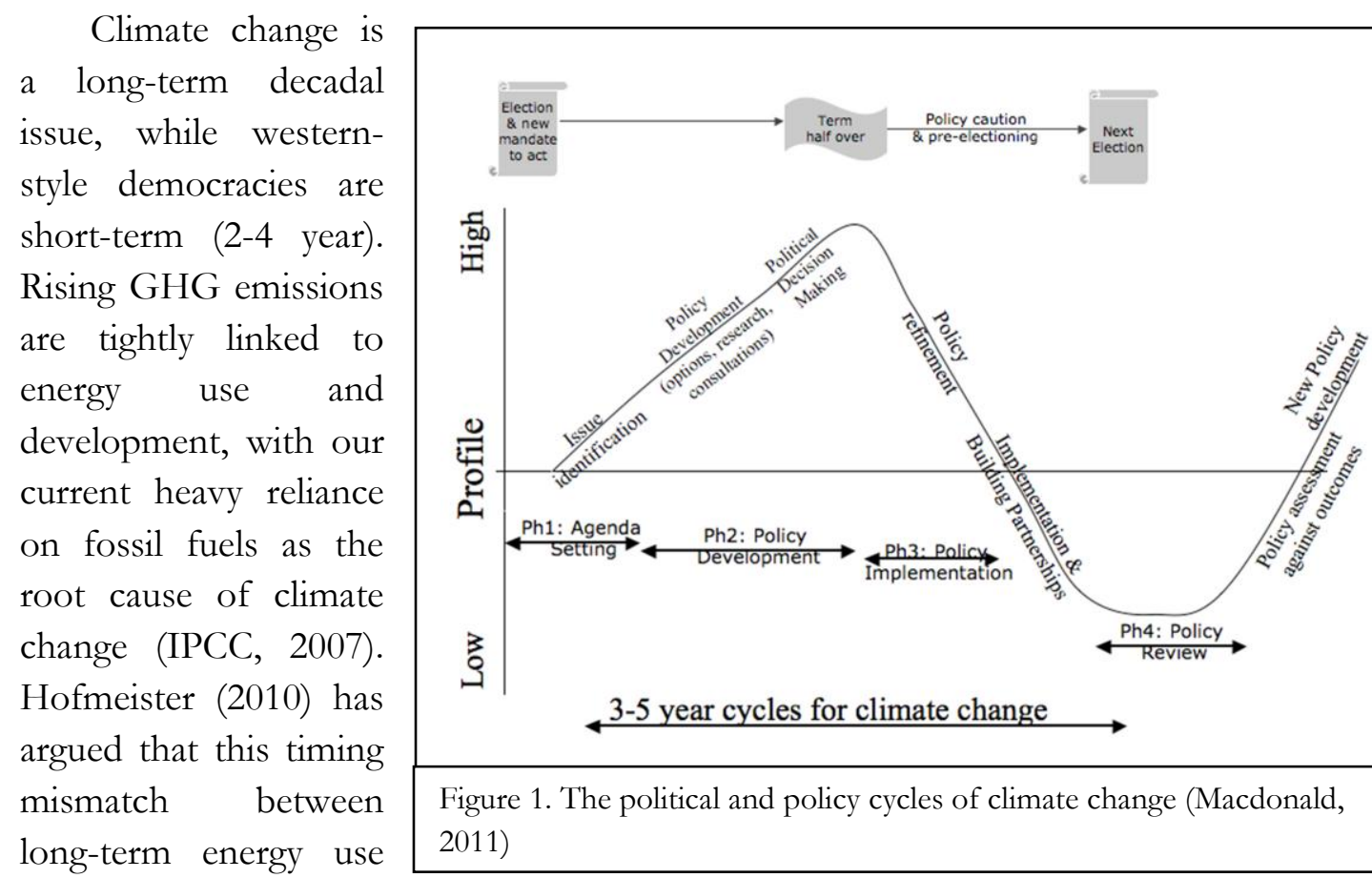

and development, resulting climate changes, and the political process is part of our fundamental problem in not making progress on these intertwined issues. Figure 1 illustrates how the election cycle overlaps with the policy cycle.

Bold new policy initiatives generally need to take place before the term of office is half over as this is generally thought to be a high-risk venture by politicians. In the second half of the elected term, politicians tend to shift to pre-electioneering and are averse to taking on any new high-risk policy or fiscal actions that may affect their electability. This second half of the term tends to be the time wherein new climate change policies that have been approved and announced can move to implementation a politically quiet activity. However, this raises the question ...how can you review the performance or effectiveness of a policy in the limited time frame of the political cycle? The results of strong policy may not be evident for years beyond the normal political cycle. Additionally, the policy review phase is often hammered by GHG data that is often two or more years out of date. This makes it difficult for policy makers to assess whether or not progress is being made. For relatively stable governments, who tend to stay in power for long periods of time (such as the People's Republic of China or the conservative-dominated government in the province of Alberta, Canada) this does not pose a great problem. However, most democracies have a great deal of political 
turnover. This can lead to constantly changing climate policy positions and strategies with few policy actions moving to implementation and consequently, little progress being made in reducing GHG emissions. The United States is a case in point; Democrat administrations try to put climate change and environmental policies in place while Republican administrations usually attempt to roll them back.

\section{Government: Agenda Setting - Key Strategic Questions}

A number of key strategic questions need to be addressed at the Agenda Setting phase of the policy cycle (Figure 1), before a government becomes committed to the development of a climate strategy. These questions include:

1. What is the real political motivation for putting this plan together?

2. How much political will or capital is there to take on this issue at this particular time?

3. As a government, how aggressive a GHG reduction target you are willing to take on vs. how much economic "pain" you can justify to voters?

4. Which is the priority - mitigation (reducing GHG emissions) or adapting to the impacts of climate change?

5. Is this the second or third variation on a jurisdiction's climate plan and how successful were the previous attempts?

Following is a discussion of these questions.

\section{What is the real political motivation for putting this plan together?}

The political motivation for developing a climate change strategy can be varied and include: 1) genuine risk mitigation based on firm convictions (e.g. the EU); 2) optics appear to be doing something with weak or no real intention of implementing the action plan (e.g. the U.S. during the George W. Bush administration, or Canada during the Harper administration to be seen to be "doing our part", 3) transitioning to a more sustainable/greener economy and realizing the economic benefits of transitioning (e.g. Iceland), and 4) setting a good example for others to follow - convince other countries to act (e.g. Tuvalu, Costa Rica).

While the answers to this question almost never appear in the final climate plan, they become crucially important in securing political support for the plan internal to the government. 


\section{How much political will or capital is there to take on this issue at this particular time?}

Again, the answer to this question usually becomes apparent as the policy development phase unfolds. Weak political support will usually translate into an equally weak plan and the converse is true for strong political support. Political will to act on climate change is a function of a number of signals that politicians are hearing: 1)how climate change ranks as a priority and the potential link to other policy issues the government is facing; 2) how strong is national/international pressure (including pressure from major trading partners) to act on climate change; 3) how the public/voters and opposition parties feel about this issue (public opinion polls) and how hard they are pressing the government for action; 4) how aggressively environmental groups and the scientific community are pressing government and how successful they are in shaping public policy; 5) what politicians themselves believe about this issue; and 6) fossil fuel industry pressure to protect their interests by limiting policy actions.

3. As a government, how aggressive a GHG reduction target you are willing to take on versus how much economic "pain" you can justify to voters?

These two interrelated questions need to be considered hand-in-hand and also link to the aforementioned political will question. The deeper the GHG reductions desired, the greater political will is needed because of the greater economic impact.

4. Which is the priority - mitigation (reducing GHG emissions) or adapting to the impacts of climate change?

For most developed countries mitigation is more important, but for most developing countries impacts and adaptation is the priority. Most climate plans end up with a unique country circumstance blend of mitigation and impacts/adaptation. This blend is reflected in the final climate plan. For example, Canadian and European plans tend to be heavy on mitigation policies and light on impacts and adaptation, while African country plans tend to be almost exclusively focused on impacts and adaptation and obtaining western financial support to fund adaptation measures.

5. Is this the second or third variation on a jurisdiction's climate plan and how successful were the previous attempts?

At the end of one policy cycle government should undertake a formal review to determine efficacy (Figure 1). What worked? What didn't? Is it time to tighten the greenhouse gas targets? Many government auditors are increasingly scrutinizing the value for taxpayer spending on delivering climate policies compared to the actual results 
achieved. For example, in the province of Alberta, the Auditor General has critiqued the government's climate change strategy and pointed out shortcomings (Alberta Auditor General, 2011). Similarly, the Auditor General in the province of British Columbia has also commented on shortcomings of the government's attempt to be carbon neutral (Auditor General of B.C., 2013).

\section{Government: The Policy Development Phase}

The entire climate change policy process is often organized into four phases: political agenda setting, policy development, implementation, and review/monitoring (Figure 1, Macdonald, 2011). The policy development phase, wherein the climate strategy or plan is forged, usually has at least five generic steps:

1. Background policy and scientific work

2. Consultation process

3. Economic/policy analysis and target setting

4. Building political support for a target and policy package

5. Refinement and final political approval

\section{Background policy and scientific work}

This step involves a number of tasks that must be undertaken in order to develop a robust and defensible strategy. These steps include the following:

1. Developing an accurate GHG inventory of historical and future emissions for the area. From this, knowing which sectors of the economy have the highest GHG emissions and their importance to the overall economy become critical. Historical emissions are usually easier to determine than future forecasts. In both cases, some simple assumptions

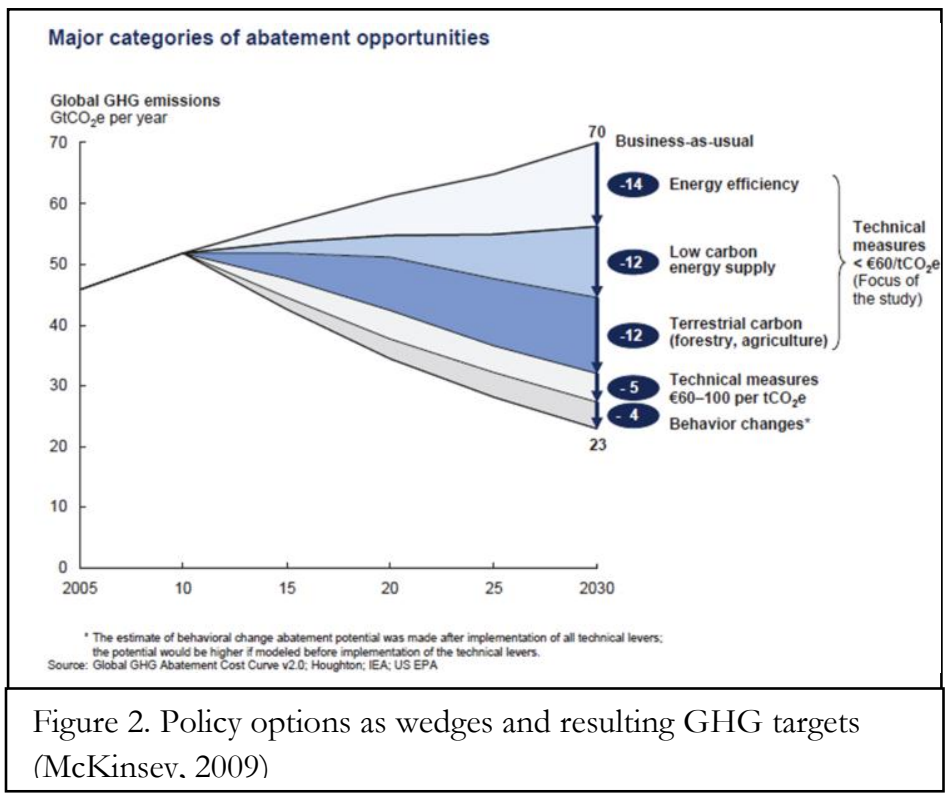


need to be made and documented in the final plan. Future forecasts of GHG emissions can have a high degree of uncertainty to them.

2. Developing a clear understanding of what the scientific community is recommending regarding global GHG reductions and what the international community might find a "credible" target and level of effort.

3. Brainstorming and economic analysis on possible mitigation policy options and the development of cost curves to rank options from best (economic return) to worst (economic loss) and how these options might add up to GHG reduction targets (Figure 2).

4. Undertaking a preliminary assessment of a country's vulnerabilities to climate impacts and quantifying this in a financial and risk management context.

\section{Consultation process}

Most governments in Canada undertake some kind of climate change consultation process to achieve a number of strategic objectives, including the following:

- obtain new innovative ideas

- test for any fatal technical, policy or economic flaws

- test for politically difficult components to sell

- build support for the final plan by active engagement of the public and industry

Having said this, jurisdictions have engaged in a full spectrum of consultation processes - all the way from plans that are developed internally by government, to "back room" discussions with key industry players to public consultation processes that are full and transparent. In Canada, the federal government is obliged to consult, to some extent, with provinces and territories on climate policy. This relates to jurisdictional ownership of fossil fuel resources, which is a provincial responsibility. Tradeoffs with the final consultation approach usually hinge on time to reach agreement (longer with transparent processes, shorter with internal) versus final buy-in and support for the plan (more for transparent processes, less for internal processes).

Some countries, like the U.S., leave consultation to lawmakers and employ lobbyist groups to represent their stakeholder views. Historically, Canada has had lengthy stakeholder consultation processes on climate change plans. At least four approaches have been taken, listed here from least to most participatory: 
- Limited consultation with key industry groups

- Single consultation once a draft plan has been developed within government (often a fait accompli)

- Multiple consultations along the way - an initial consultation before getting started, a mid-point review once some progress has been made, and a final consultation when a draft plan is ready.

- Participatory "consultation" in which stakeholders are given broad authority to actually help the government develop the final plan.

Again, the final selection of which consultation process to choose is often a matter of trade-offs and political commitment. Limited consultations tend to be more expeditious, but tend to alienate stakeholders leading to poor public and industry support for the final climate plan. Broader consultation approaches tend to take a very long time, but may have wide support once agreement is reached. However, participatory consultation may make it difficult to reach agreement given the multiple points of view that are usually brought forward. Governments can also use extensive consultations on climate policy to stall for time and avoid taking action.

Economic/policy analysis

and target setting

This stage is where the real detailed work gets done. It often begins with a policy analysis to define a "basket" of approaches that might work in a particular jurisdiction. Cost curves are determined at this point. Cost curves set out a range of reduction options, how many

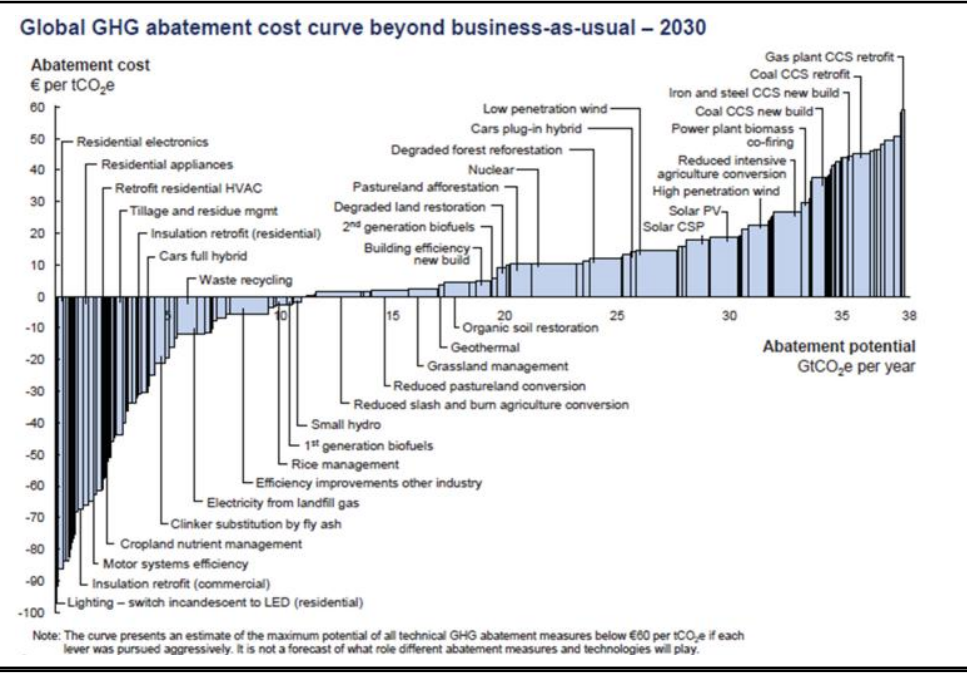

Figure 3. Global GHG abatement cost curve beyond business as usual -2030 (McKinsey, 2009)

tonnes they will deliver and for what carbon price. Policy options are then put in an economic model to determine what kind of reductions can be achieved, the impact to the economy, and in what timeframe. Alternatively, some economic models allow the user to set a price for carbon (e.g. $\$ 10 /$ tonne, $\$ 50 /$ tonne, $\$ 100 /$ tonne, etc.) and the model produces a suite of 
policy options that are achievable at these various carbon price signals (Figure 3). A simplified first approximation can be derived by taking the jurisdiction's annual GHG emission, deciding on a percent reduction target and then reading off the cost curve what this reduction is likely to cost. Cost curves also suggest which policy options to proceed with first (most economic at the far left) to last (i.e. most expensive - far right of the graph).

\section{Building political support for a target and policy package}

Once the analysis stage is complete, a discussion with political decision makers can begin. At this point, all of the key strategic questions discussed earlier need to be carefully considered. In particular, the question of depth of targets versus economic cost versus political salability need to be finalized. GHG reduction targets continue to be the political and scientific focus of climate plans/strategies. International credibility and reputation also comes to bear at this stage - too light of a target will fail to gain international credibility, while too aggressive a target is unlikely to be approved domestically - due to anticipated high costs. Questions invariably arise as to whether the intent is to be a leader, a laggard/minimalist, or to fall in line with what other countries are proposing or actually doing. This is not unlike the Goldilocks and the three bears story - not too hot - not too cold - somewhere in the middle is often just right - often regardless of what the science is saying! Once a draft target and its associated policy measures are agreed upon in the lead Ministry/Department, it is this Minister's/ Secretary's job to convince cabinet colleagues and the Opposition that this is the way to proceed.

\section{Refinement and final political approval}

The initial climate change plan/strategy with its targets and policies is invariably not the final version that is released to the public. Once politicians begin to "shop the plan around" to colleagues, a myriad of concerns arise that must be addressed. Compromises, additions, deletions and changes are invariably made to the plan. Unfortunately, in Canada at least, the draft climate plan often drifts away from something that represents sound policy, scientific, and economic analysis to something that is politically acceptable. The final product may bear little semblance to the original draft developed internally or through consultations.

However, politicians with a strong understanding of the economics and analysis that went into the initial draft plan can be very effective in minimizing this "drift". If a politician has done their job well with behind the scenes discussions with cabinet 
colleagues, when the final plan comes to cabinet for approval, it passes relatively easily. In some jurisdictions a legislative body must approve the climate plan and this in turn can add months or years to the approval process and generate a multitude of policy changes.

Because climate change is a global issue, and so political, the national/provincial/ state leader (President, Prime Minister, Governor, Premier) often takes the lead in releasing the plan and attending to follow-up media interactions. The release of climate plans is often done at major national or international climate change events to maximize their exposure. This is often followed up by a series of announcements that progressively release any details that are available. This release process also builds public interest and support for the plan. For a serious climate change policy initiative, the strategy/plan usually then moves back to the administrative side of government for implementation.

\section{Business and Climate Change Strategies}

Businesses face climate change risks related to being regulated for carbon-especially among high emitting companies-and also risks related to the real impacts of climate change and resulting financial losses. Some companies do not experience either of these risks and may have considerable new

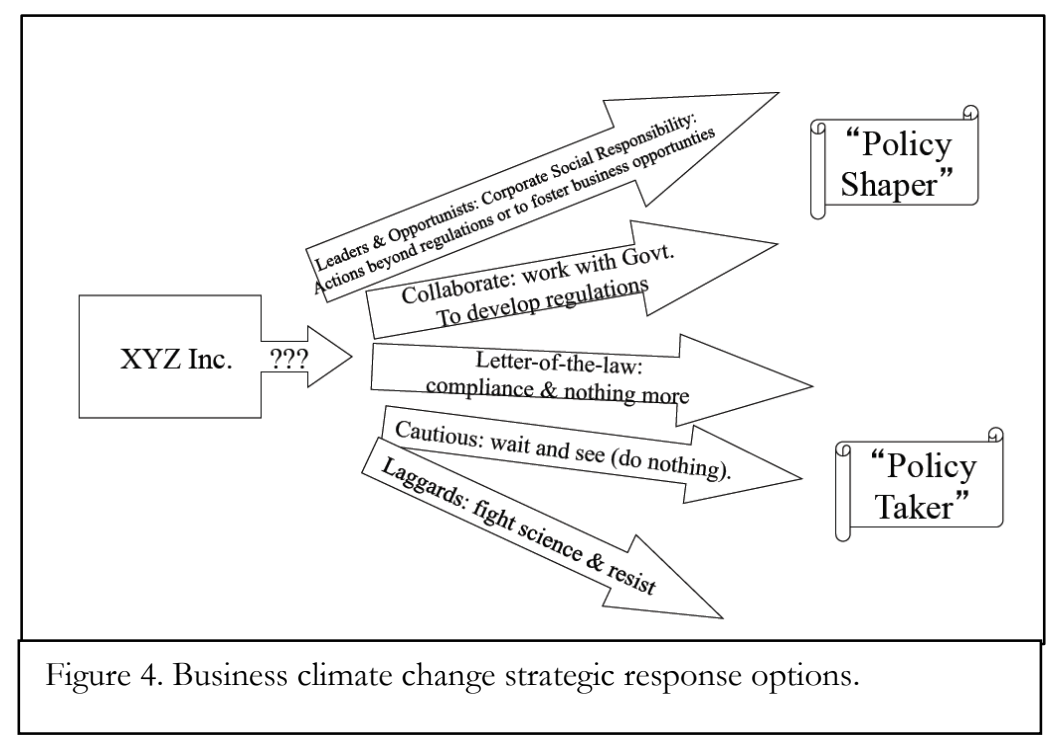
business opportunities. Figure 4 illustrates a number of strategic options businesses have in responding to climate risks. Businesses that choose options in the upper half of Figure 4 tend to become shapers of government policy, while those in the lower half tend to become the recipients of policy without much of a role in developing it. 
Carbon Regulatory Risk

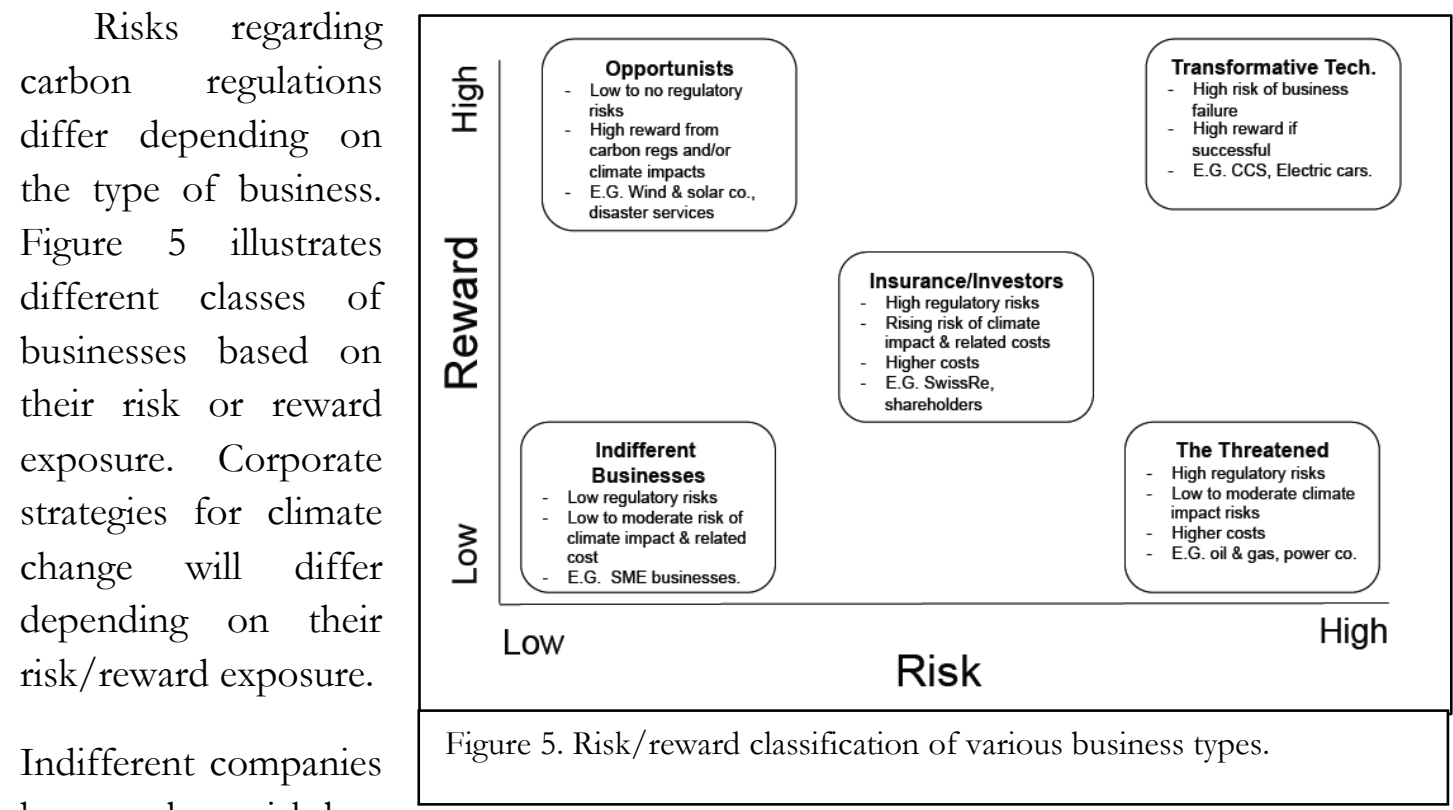

have a low risk-low

reward profile, but could still be at risk from the real impacts of climate change (e.g. extreme weather events, rising sea levels). Threatened companies have high greenhouse gas emissions profiles and are at the highest risk of being regulated for "carbon", thereby increasing their costs of doing business. Opportunist companies have a high reward-low risk framework and could prosper under carbon regulations, as market share shifts their way. Investors face moderate risks of exposure to carbon regulations, unless they take measures to reduce their risks. For example, some investors are shifting away from the fossil fuel sector to the clean technology sector. The re-insurance industry is becoming increasingly concerned with the rising costs of severe weather events that are likely becoming more frequent or intense in a warming world. The Transformative Tech sector faces high risks of not succeeding in the market, but also faces very high rewards if carbon regulations become more stringent and they gain market share.

\section{Climate Impact Risks}

Companies of any size could face financial losses related to the impacts of climate change. Homeowners and small businesses can face hundreds of thousands to million dollars losses from the higher frequency or intensity of hurricanes, tornados, floods or severe thunderstorms. Larger corporations can face losses to capital infrastructure assets or lost productivity in the 10 s to 100 s of million dollars from a variety of climate related 
problems (e.g. damaged offshore drilling rigs from hurricanes, lost revenues for hydroelectric plants due to low rainfall, damaged industrial plants related to river flooding). Some companies are using risk management approaches to manage their climate impact risks.

\section{Summary}

There is a high degree of scientific certainty that burning fossil fuels (and cutting down forests) is altering the climate system and this will bring mostly harmful impacts to humans and ecosystems. Most governments accept the science and use climate change strategies and action plans to signal their intent to take policy action. Businesses are also responding by developing climate change strategies to either hedge their risk of being regulated, hedge their risk related to severe weather events, and/or to take advantage of climate business opportunities.

\section{Acknowledgements}

This paper was improved considerably by the constructive suggestions of two anonymous peer reviewers. Dr. Jeremy Macdonald, Stevens Institute of Technology, New Jersey also provided many helpful suggestions. Betty Macdonald and the students of MacEwan University's EASC 373 course also provided valuable advice.

* Author: Donald E. Macdonald is a Lecturer at MacEwan University and former senior climate change policy advisor with the Alberta Government. Email: MacdonaldD26@macewan. 


\section{References}

Auditor General Alberta (2011). Climate Change and Emissions Management Fund -Use of Offsets for Compliance with Regulations Retrieved April 4, 2013, from http://www.oag.ab.ca/?V_DOC_ID=974

Auditor General of British Columbia (2013). An Audit of Carbon Neutral Government. Retrieved April 12, 2013, from http://www.bcauditor.com/pubs/2013/report14/audit-carbon-neutral-government

Cook, J., Nuccitelli, D., Green, S., Richardson, M., Winkler, B., Painting, R., Way, R., Jacobs, P. and Skuce, A. (2013). Environ. Res. Lett. 8024024 doi:10.1088/1748$9326 / 8 / 2 / 024024$

Hofmeister, J. (2010). Why we hate the oil companies, Palgrave MacMillian.

IPCC, 2007: Climate Change (2007). Synthesis Report. Contribution of Working Groups I, II and III to the Fourth Assessment Report of the Intergovernmental Panel on Climate Change [Core Writing Team, Pachauri, R.K and Reisinger, A. (eds.)]. IPCC, Geneva, Switzerland, 104 pp.

Macdonald, D. E. (2011). Climate change policy 101. MacEwan University, Earth Common Journal, Vol. 1, No. 1.

McKinsey, (2009). Pathways to a Low-Carbon Economy (version 2 of the Global Greenhouse Gas Abatement Cost Curves). McKinsey \& Company. Retrieved April 12, 2013 from https:// solutions.mckinsey.com/climatedesk/default.aspx

NRTEE (2012). Reality Check: The State of Climate Progress in Canada, National Roundtable on the Environment and the Economy. Retrieved April 12, 2013, from http:/ / collectionscanada.gc.ca/webarchives2/20130322165455/http:/ nrteetrnee.ca/reality-check-the-state-of-climate-p 